\title{
Numerical estimation of natural ventilation of cubical urban arrays with different packing density
}

\author{
Saidatul Sharin Shuhaimi ${ }^{1}$, Sheikh Ahmad Zaki ${ }^{1, *}$, Mohamed Sukri Mat Ali ${ }^{1}$, and Nurul Huda Ahmad ${ }^{2}$, Fitri Yakub $^{1}$ \\ ${ }^{1}$ Department of Mechanical Precision Engineering, Malaysia-Japan International Institute of Technology, Universiti Teknologi \\ Malaysia, 54100 Kuala Lumpur, Malaysia \\ ${ }^{2}$ Engineering Department, UTM Razak School of Engineering and Advanced Technology, Universiti Teknologi Malaysia, Kuala \\ Lumpur, 54100 Kuala Lumpur, Malaysia
}

\begin{abstract}
In an urban environment where buildings are closely packed, natural ventilation performance is undesirably disturbed by the effect of surrounding buildings. Cross-ventilation refers to the regulation of air within a building, which is essential in providing good air quality and thermal comfort for the occupants. Thus, this study focuses on the impact of packing density on ventilation rate of cross-ventilated buildings. The numerical estimation is performed by means of computational fluid dynamic (CFD) using the Reynolds Averaged Navier-Stokes (RANS) with RNG $\mathrm{k}-\varepsilon$ (RNG) turbulence model. Three configurations of simplified generic cubes which are regularly aligned with packing density of $25 \%, 35 \%$, and $50 \%$ were considered. Velocity distribution around and inside the buildings as well as the ventilation rate are analysed. The case with packing density of $25 \%$ exhibits a reduction of $90 \%$ in the ventilation rate compared to the isolated case and continues to decrease as the packing density increase up to $35 \%$. However, further increase of packing density up to $50 \%$, slightly increases the ventilation rate. Hence, the result of this study imposed that surrounding buildings have a substantial influence on ventilation performance of cross-ventilated buildings.
\end{abstract}

\section{Introduction}

Living in a period of tremendous technological development and densely inhabited cities, exploitation of natural ventilation into built environment for the construction of new buildings like residential, commercial buildings and public facilities are substantial for a country like Malaysia. Natural ventilation is conceptually simple; however the design to fully utilize the source can be a challenge. Ventilation performance is affected by microclimate (wind speed, wind direction, temperature and humidity), building form (building shape, size of openings and orientation) and surrounding (topography and location). Great ventilation has positive impact on occupant for the liveability of city. As the density of a city increase, occupants experience thermal discomfort and require usage of cooling system commonly in the form of mechanical ventilation. As a result, the quality of air decreases and larger energy is consumed. Natural ventilated building, relying on difference in temperature and wind induced pressure is the most common form of natural ventilation [1].

The concept of natural ventilation is not contemporary. It has been exploited for many centuries long before mechanical ventilation is invented. In cross ventilation, air enters from windward façade moving through leeward façade by openings installed on opposite sides of the enclosed area by wind-induced pressure difference between the opposite openings.
Previous studies demonstrated the benefits of cross ventilation compared to single sided ventilation $[2,3]$. An experiment on a cross ventilation model revealed that the discharge coefficient on inlet did not fluctuate significantly with direction of wind [4]. A series of wind tunnel experiment were conducted to examine the wind load on a low-rise structure within an array of buildings of various spacing [5]. On top of that, both experimental and numerical methods have been utilized to investigate the effect of opening configurations on cross ventilation rate $[6,7]$. Despite the exhaustive research in this field, the influence of surrounding buildings has only been explored in a limited manner. One can be notable is a study on the significance of separation distance and building disposition in enhancing the ventilation rate of a cross ventilated buildings [8]. An experimental study using wind-tunnel suggested that the pressure coefficient of a cube array with solid walls decrease as the packing density increase [9]. Whereas a study using large-eddy simulation for heterogeneous buildings revealed that as packing density increase, a larger sheltering effect is observed towards surrounding buildings [10]. However, a similar study on a building with opening is still inadequate to strengthen the hypothesis. Thus, this paper aims to reveal how packing density affects ventilation rate in an urban environment with the aid of CFD.

\section{Methodology}

\footnotetext{
Corresponding author: sheikh.kl@utm.my
} 


\subsection{Model Validation}

The building model used in this validation is shown in Figure 1. The building has a size of $0.3 \mathrm{~m} \times 0.3 \mathrm{~m} \times 0.15$ $\mathrm{m}$ (width $\times$ length $\times$ height) with two openings of size $0.06 \mathrm{~m} \times 0.03 \mathrm{~m}$ (width $\times$ height) located at the centre of both windward facade and leeward facade. The thickness of the wall is $10^{-6} \mathrm{~m}$. It is a cross ventilated building replicated from the wind tunnel experiment [4].

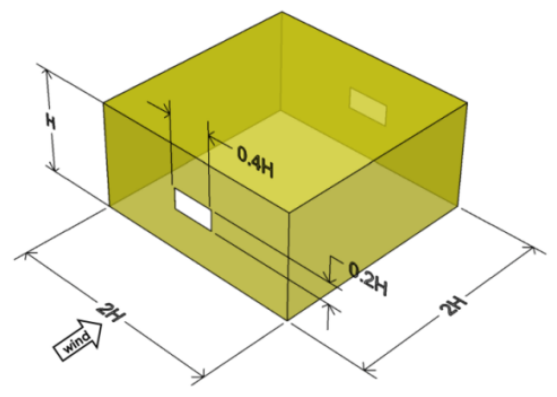

Fig. 1. Schematic view of building model $(\mathrm{H}=0.15 \mathrm{~m})$.

The inlet velocity profile is defined by the power law expression

$$
U(z)=U_{r e f}\left(\frac{z}{H}\right)^{n}
$$

where $\mathrm{U}_{\text {ref }}$ is the velocity at building height in $\mathrm{m} / \mathrm{s}, \mathrm{H}$ is the building height in metres, $z$ is the vertical location also in metres, and $n$ is the power coefficient with a value of 0.25 . The inlet velocity profile of the $\mathrm{RNG}$ model used in the present study is plotted against $Z / H$ to fit the velocity profile used in the wind tunnel experiment [4], as shown in Figure 2.

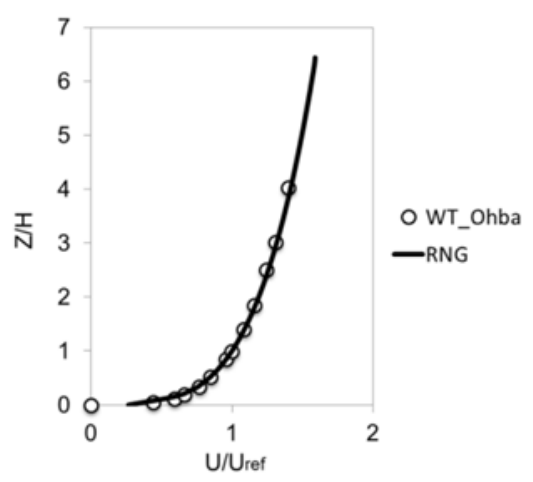

Fig. 2. Inlet velocity profile.

The dimension of the domain was determined based on the existing best practice guidelines [9], however the outflow region located at the leeward area of the domain was not determined according to the guidelines. The size of the computational domain is $17 \mathrm{H} \times 12 \mathrm{H} \times 6.5 \mathrm{H}$.

The velocity inflow is prescribed at $\mathrm{X}=-7.5 \mathrm{H}$ in the upstream path perpendicular to the opening while the outflow boundary is placed at $\mathrm{X}=7.5 \mathrm{H}$ downstream from the leeward building façade to the outlet plane. Width of the domain is set at $\mathrm{Y}= \pm 5 \mathrm{H}$ from the sidewalls of the building, whereas the height of the domain is $Z=6.5 \mathrm{H}$. Zero flux condition is applied on the lateral and upper boundaries meanwhile the building and the ground are set with wall functions.

Figure 3 (a) and (b) compares the velocity vector inside and around the building for simulation and experiment [4] respectively. Comparing both of these velocity vectors, the result shows a good agreement in general. The incoming flow is separated near the windward roof. However, a small discrepancy can still be observed near the edge of the roof where RNG under predict the separation flow compared to the experiment. A recirculating eddy can be observed on the upwind face on both RNG and wind tunnel case. The RNG model is able to capture the downward tendency of the flow passing through the windward opening, similar to that of wind tunnel. The flow inside the building shows similar behaviour as the experiment and the weakening flow right after the leeward openings are also captured within acceptable accuracy.

a)

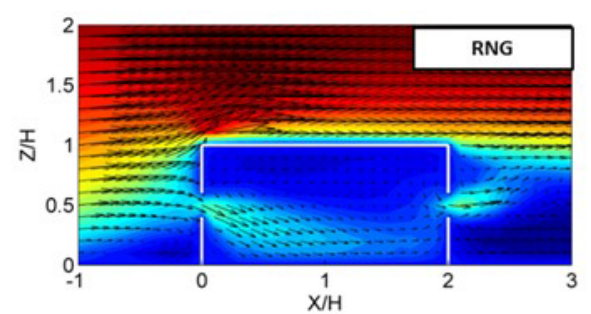

b)

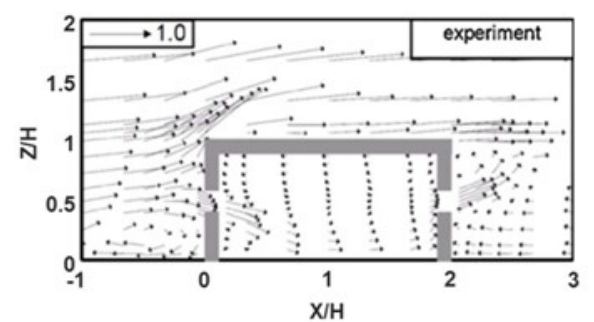

Fig. 3. Velocity vector and contour for a) RNG and b) Wind tunnel by Ohba et al.[4]

Ventilation rate in the present study is calculated directly from the airflow passing through the inlet of the openings, expressed as

$$
Q=\bar{U} \times A
$$

where $\mathrm{Q}$ is the ventilation rate in $\mathrm{m}^{3} / \mathrm{s}, \overline{\mathrm{U}}$ is the mean velocity at opening in $\mathrm{m} / \mathrm{s}$, and $\mathrm{A}$ is the area of opening in $\mathrm{m}^{2}$. The reference ventilation rate, $\mathrm{Q}_{\text {ref }}$ are defined as

$$
Q_{\text {ref }}=\bar{U}_{r e f} \times A
$$

where $\mathrm{Q}_{\text {ref }}$ is the reference ventilation rate in $\mathrm{m}^{3} / \mathrm{s}$ and $\overline{\mathrm{U}}_{\text {ref }}$ is the mean velocity taken at building height.

Grid size located within the building area is refined up to $\mathrm{H} / 64$ to certify adequate degree of grid independence of the result. The normalized volumetric flow rates of three different grid sizes on the openings are compared with that of experiment in Table 1 . The coarse grid size over predicts the ventilation rate by about $20 \%$ difference when compared to the experimental value. Hence the coarse grid size is not preferable in this study due to higher discrepancy. The medium grid size predicts the ventilation rate reasonably 
with only $6 \%$ of discrepancy, while the fine grid size has a value almost identical to the experimental data with a discrepancy about $2 \%$ only. Hence the selection of fine grid size was used for the follow-up investigations.

Table 2. Normalized ventilation rate of different grid size.

\begin{tabular}{|c|c|}
\hline Grid Size & $\mathbf{Q} / \mathbf{Q}_{\text {ref }}$ \\
\hline Coarse $(\mathrm{H} / 12.5)$ & 0.547 \\
\hline Medium $(\mathrm{H} / 25)$ & 0.483 \\
\hline Fine $(\mathrm{H} / 64)$ & 0.465 \\
\hline Wind tunnel & 0.456 \\
\hline
\end{tabular}

\subsection{Buildings Configurations and Computational Domain}

Simplified generic cube was used to represent urban environment. The building model investigated in present study is a cross-ventilated building that is used in the validation exercise. The three dimensional computational domain composed of nine buildings, arranged in a regularly aligned manner. The building with openings is located in the centre of the arrangement. Three urban configurations are defined by varying the separation distance, $\mathrm{W}$, between the buildings to represent packing density, $\lambda_{\mathrm{p}}$ of $25 \%$ (PD25), 35\% (PD35) and 50\% (PD50) as in Figure 4. The size of the computational domain varies as packing density changes [11]. The wind direction is assumed to be normal to the opening of the building.

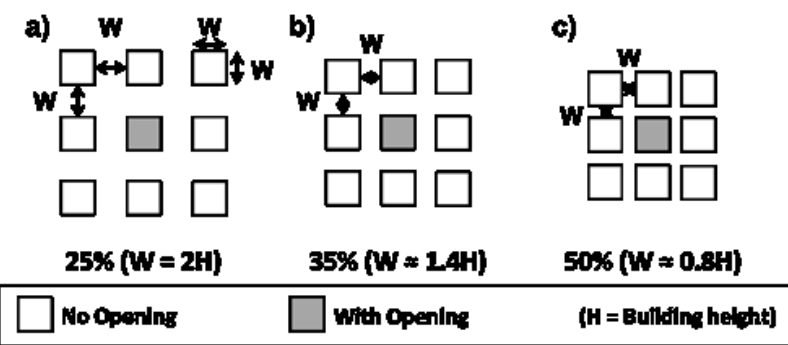

Fig. 4. Configuration of different packing density from top view. a) PD25 b) PD35 c) PD50.

\subsection{Boundary Conditions and Turbulence Model}

All the boundary conditions used in the validation process are applied onto the case study. Inlet velocity profiles of power law are expressed at the inlet boundary using Equation 3. All the walls and the ground of the buildings are treated with wall function. RNG turbulence model is applied due to its superior performance in validation exercise $[12,13]$. Open source software named OpenFOAM with version 2.3.1 is used to resolve the RANS equation of the RNG turbulence model considering its reliability in simulating airflow distribution in buildings [14]. Pressure velocity coupling is solved using the SIMPLE algorithm. Second order discretization scheme are used for the viscous terms of the governing equations. Convergence is obtained when the scaled residuals reached a minimum of $10^{-6}$ for pressure and $10^{-7}$ for dissipation rate, kinetic energy, and velocity.

\section{Results and Discussion}

\subsection{Ventilation rate}

A graph of normalized ventilation rate, $Q / Q_{\text {ref }}$ versus packing density in Figure 5 is plotted. The trend exhibited that ventilation rate on the openings decreases as packing density increases from $0 \%$ (isolated building) to $35 \%$. The building experienced a reduction of almost $90 \%$ as it is surrounded by other buildings with no opening as in PD25. This figure is slightly higher than the one mentioned in previous study [15] which is most probably due to disparity in the building configuration and opening size. The normalized ventilation rate dropped to nearly 0 in PD35 signifying a very low ventilation performance in the building. However, the ventilation rate is slightly increased as the packing density is increased to $50 \%$ in PD50. The reduction of ventilation rate can be explained by the fact that smaller pressure difference is produced on building surfaces as the packing density increase [9].

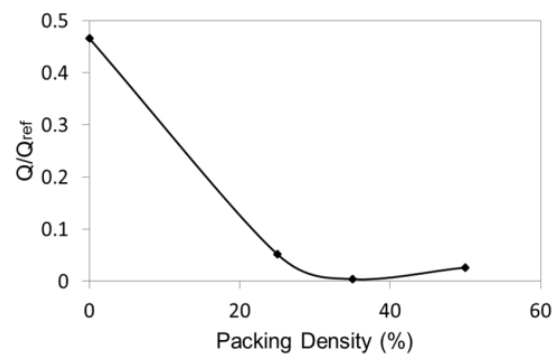

Fig. 5. Normalized ventilation rate for different packing density.

Figure 6 visualize the flow distribution of each case in terms of vectors and contours. A skimming flow regime [16] is observed inside the street canyon perpendicular to the wind direction in all cases. Nevertheless, the flow distribution is slightly modified as the distance between adjacent buildings is closer. PD25 shows the higher amount of flow entering the inlet compared to others. The flow inside building becomes weaker in case of PD35 and PD50. In contrast with PD25 and PD35, the flow in PD50 is observed to enter the building through the outlet on the leeward wall and escape through the windward opening. This indicates that ventilation behaviour depends on the characteristic of flow inside street canyon. 
a)

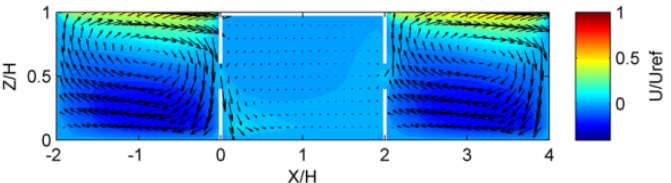

b)

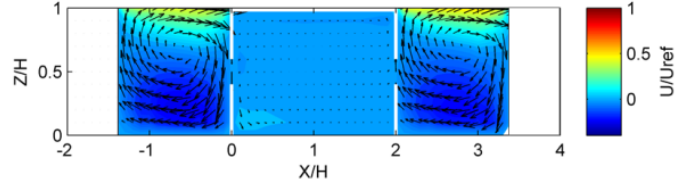

c)

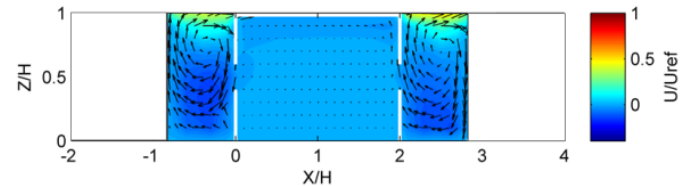

Fig. 6. Velocity vector and contour for a) PD25 b) PD35 and c) PD50

The negative value of $U / \mathrm{U}_{\text {ref }}$ taken at the centre of the inlet as in Figure 7 justified the aforementioned statement regarding the direction of wind at the opening for case PD50.

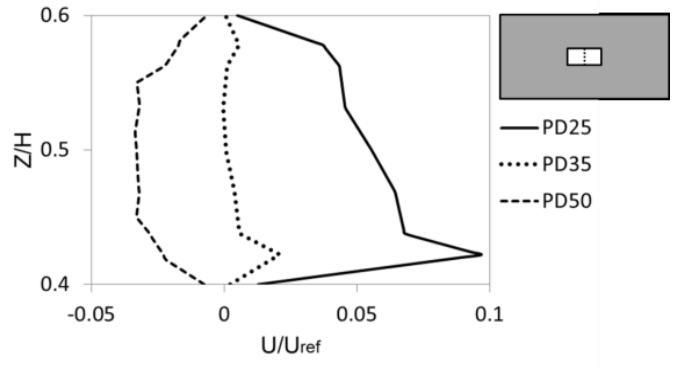

Fig. 7. $U / \mathrm{U}_{\text {ref }}$ at the centre of the inlet opening.

\section{Conclusions}

One of the key elements in a sustainable environment is the exploitation of natural ventilation. Nevertheless, the utilization of natural ventilation is hampered due to rapid urbanization in the recent years.

CFD simulations in investigation of cross ventilation buildings with different packing densities are presented in this paper. 3D steady-state RANS approach is paired with the RNG $\mathrm{k}-\varepsilon$ model to provide closure for the turbulence model. Model validation is conducted using a reference case adopted from wind tunnel experiment, where it is replicated into computational model and the vertical velocity profile from both models are compared. The result shows a very good agreement with the experimental data; therefore proved the reliability of the RNG k- $\varepsilon$ two-equation model in simulation building ventilation. Sensitivity study is conducted to choose the appropriate grid size for the study and to justify the selection. The verification study gives more insight on the effect of different grid size on the accuracy of the solution, where finer grid size exhibits superior accuracy compared to coarser grid size.

The case study focused on three different packing densities, particularly $25 \%, 35 \%$, and $50 \%$. The effect of packing density on ventilation rate are examined by calculating the normalize ventilation rate, $\mathrm{Q} / \mathrm{Q}_{\mathrm{ref}}$ of hypothetical urban environment in regular alignment.
The ventilation rate on the openings are analysed, calculated, and compared. Further analyses are done to attain more perspicacity of the behaviour of the flow.

For packing density of $25 \%$, the ventilation rate dropped about $90 \%$ compared to the reference case. The ventilation rate becomes weaker when the packing density is increased to $35 \%$. Contradictorily, a further increase in packing density up to $50 \%$ shows a slight increase with a negative sign in ventilation rate indicating the opposite direction of airflow compared to the ventilation rate of packing density $35 \%$. Comparing all three cases simultaneously, it can be confirmed that the ventilation performance strongly depends on the area packing density as it affects the flow regimes inside the canyon. Hence, the fundamental relation between ventilation performances of cross-ventilated buildings to packing density is explored.

This research was financially supported by the AUNSEEDNET Grant (Vot 4B229) project of Universiti Teknologi Malaysia.

\section{References}

1. R. Teppner, B. Langensteiner, W. Meile, G. Brenn, and S. Kerschbaumer, Air change rates driven by the flow around and through a building storey with fully open or tilted windows: An experimental and numerical study, Energy and Buildings. 76:640-653 (2014).

2. K. Niachou, S. Hassid, M. Santamouris, and I. Livada, Comparative monitoring of natural, hybrid and mechanical ventilation systems in urban canyons, Energy and Buildings. 37(5): 503-513. (2005).

3. N.F.M. Kasim, S.A. Zaki, M.S.M Ali, N. Ikegaya, and A.A Razak, Computational study on the influence of different opening position on wind-induced natural ventilation in urban building of cubical array, Procedia Engineering. 169:256-263 (2016).

4. M. Ohba, K. Irie, and T. Kurabuchi, Study on airflow characteristic inside and outside a cross-ventilation model and ventilation flow rates using wind tunnel experiments, Journal of Wind Engineering and Industrial Aerodynamics. 89 (14-15): 1513-1524 (2001).

5. B.E. Lee, M. Hussain, and B. Salman, A method for the assessment of the wind-induced natural ventilation forces acting on low rise building arrays, Building Services Engineering Research and Technology. 1(1): 35-48 (1980).

6. P. Karava, T. Stathopoulos, and A. Athienitis, Airflow assessment in cross-ventilated buildings with operable façade elements, Building and Environment. 46(1): 266-279 (2011).

7. J. Seifert, Y. Li, J. Axley, and M. Rösler, Calculation of wind-driven cross ventilation in buildings with large openings, Journal of Wind Engineering and Industrial Aerodynamics. 94(12): 925-947 (2006). 
8. J. O. P. Cheung, and C. H. Liu, CFD simulations of natural ventilation behavior in high-rise buildings in regular and staggered arrangements at various spacing. Energy and Buildings. 43(5): 1149-1158 (2011).

9. S. A. Zaki, A. Hagishima, and J. Tanimoto, Experimental study of wind-induced ventilation in urban building of cube arrays with various layouts, Journal of Wind Engineering and Industrial Aerodynamics, 103: 31-40 (2012).

10. A.F. Mohammad, S.A. Zaki, M.S.M Ali, H. Aya, A.A Razak, M. Shirakashi and N. Arai, Large eddy simulation of wind pressure distribution on heterogenous buildings in idealised urban models. 78: 3055-3060 (2015).

11. J. Franke, A. Hellsten, H. Schlünzen, and B. Carissimo, Guideline for the CFD simulation of flows in the urban environment: COST Action 732 Quality Assurance and Improvement of Microscale Meteorological. 1-52 (2007).

12. A. D. Ferreira, A. C. M. Sousa, and D. X. Viegas, Prediction of building interference effects on pedestrian level comfort, Journal of Wind Engineering and Industrial Aerodynamics. 90(4-5): 305-319 (2002).

13. Q. Chen, Ventilation performance prediction for buildings: A method overview and recent applications, Building and Environments. 44(4): 848-858 (2009).

14. N. F. M. Kasim, S. A. Zaki, M.S. Mat Ali, A.F. Mohammad and A. Abd Razak, $A$ verification and validation study of CFD Simulation of wind-induced ventilation on building with single-sided opening, Applied Mechanics and Materials. 554: 696-700 (2014).

15. Y. Tominaga and B. Blocken, Wind tunnel experiments on cross-ventilation flow of a generic building with contaminant dispersion in unsheltered and sheltered conditions, Building and Environment, 92:452-461 (2015).

16. T. R. Oke, Street design and urban canopy layer climate, Energy and Buildings. 11(1-3): 103-113 (1998). 